AP: Ontine Journat in Public Archaeology Special Volume 3 - 2018 p. 249-276

\title{
From Plastered Skulls to Palliative Care: What the Past Can Teach Us About Dealing with Death
}

\author{
Lindsey BÜSTER*, Karina CROUCHER*, \\ Jennifer DAYES*, Laura GREEN* and Christina FAULL** \\ * University of Bradford \\ ** LOROS Hospice Leicester
}

Received: 25/08/2017 - Accepted: 26/06/2018

\begin{abstract}
Modern, advanced healthcare detects and monitors long-term and life-limiting illness more comprehensively than ever before. However, death is now often considered medical failure, and is a virtually taboo topic of conversation in daily life. At a time when the societal relevance of archaeology is under scrutiny more than ever before, the AHRC-funded Continuing Bonds Project - a collaboration between archaeology and palliative care - explores the potential of the past to promote discussion. Not only does archaeology illuminate the diversity of practice surrounding death, the past provides a safe, distanced platform for considering death, dying and bereavement today. Through archaeological and ethnographic case studies, health and social care professionals and students consider topics such as place, choice and identity, in both personal and professional life. This article examines participant responses to a variety of archaeological material and presents post-workshop reflections which demonstrate the success of archaeology in opening up conversations and increasing confidence in discussing this most enduring and problematic of life events.
\end{abstract}

\section{Keywords}

archaeology, bereavement, care, continuing bonds, death practices, palliative care 


\section{Introduction}

Death in a modern world

"Death is treated by medical science as a momentary event that can be delayed until a suitable time" (Quested and Rudge 2003: 544)

In an increasingly globalized and technology-driven world, advanced healthcare allows for the detection and monitoring of long term and life-limiting illness earlier and more comprehensively than ever before. People are now increasingly aware of the dying process in the weeks, months and years before death, with a host of interventions employed to prolong life for as long as possible. It might be assumed that this advanced warning has helped individuals to better come to terms with their own mortality. The opposite appears, however, to be true (cf. Kellehear 2007). Much medical and health care revolves around a series of ever more drastic interventions designed to preserve life at all costs; indeed, problems often arise in determining the point of referral to a palliative care team (e.g. Walshe et al. 2008; Luce 2010; Campos-Calderón et al. 2016). Death itself is frequently seen as medical failure (cf. Gellie et al. 2015). Thus it is often a taboo topic of conversation (Becker 1973; Solomon et al. 1998), both with those at the end of their lives, and with the recently (and not so recently) bereaved (Cox et al. 2013; although see Walter 1991 and Chapple et al. 2015 for discussion regarding the contextual nature of this taboo). This avoidance of the topic persists despite guidelines reaffirming the importance of honest and open communication (Buckman 1993; DH 2008; SGHD 2008) and recognition that dying is a normal part of life (World Health Organisation 2012). Furthermore, death has been increasingly outsourced and professionalized (particularly, in the UK, since the founding of the NHS in 1948), which has shielded society from the physical changes that the body undergoes during and immediately after death. This has, in turn, increased the workload and emotional stress of nurses, whose roles now include not just physical and emotional support of dying patients, but that of their grieving relatives too. Indeed, much recent 
nursing literature concerns the emotional impact and coping strategies that nurses employ daily in their encounter and reencounter with death, dying and bereavement (e.g. Hopkinson et al. 2005).

Manuals detail the processes needed to 'deal' with virtually every kind of death situation, in an attempt to 'bring order to the chaos of death' (Quested and Rudge 2003: 555). Where past societies acknowledged the inherent liminality of the dead and dying, an increasingly medicalized and secularized approach has today attempted to reduce and contain this ambiguity, not least through ever-more precise 'definitions' of moments and modes of death. This approach has, however, created further unforeseen ambiguities, and, in the most extreme cases, has created new 'categories' of people (such as donors awaiting organ retrieval): not quite living but not yet fully dead. This liminal category of individuals is itself subject to a great deal of recent literature (e.g. Crandall 1987; Johnson 1992) and appears globally to be particularly problematic for nurses and relatives alike.

In the face of these theoretical challenges, an aging population, and a UK health service under strain, there has been increasing reaction against this protectionist approach to death. Central to this are conversations, not just between the elderly and infirm and the medical professionals assigned to them, but involving everyone, whatever their age and health status. Bereavement has now also been unshackled from the straitjacket of traditional models which have, in the past, assumed a linear progression from grief to detachment and/or acceptance (e.g. Bowlby 1980; Kubler-Ross 1996), towards a more holistic approach which acknowledges its fluid and protracted nature. One example of this is the persistence of 'continuing bonds' (e.g. Klass et al. 1996; Walter 1996; Stroebe et al. 2012) between the living and the dead.

This new understanding of bereavement can be seen in initiatives such as Dying Matters Awareness Week (overseen by the Dying Matters coalition established in 2009; Dying Matters 2018), which encourages people, young and old, to talk more openly about death and their end-of-life plans. Others include local communityled collaborations such as Pushing Up Daisies in Todmorden, West 
Yorkshire (Pushing Up Daisies 2018), which promote conversations around death, dying and bereavement in daily life. Meanwhile, Death Cafés (Impermanence 2018) - developed by John Underwood in 2011 from Swiss 'Cafés Mortels' and now held throughout the UK - provide spaces to talk informally about topics surrounding death, dying and bereavement (traditionally over tea and cake). Death is also now much more accessible in the digital world, either through news stories or online discussions via social media, including profiles and memorial pages (cf. Sofka et al. 2012). Despite this upsurge in public awareness, most people still die in hospital, without advanced care plans. This leaves doctors, and nurses in particular, to preside over difficult conversations with a diverse range of people in varying circumstances; conversations and circumstances for which they have often had little formal training (e.g. Kent et al. 2012).

\section{How can archaeology help? : The Continuing Bonds Project}

It is, in relation to big societal questions - such as coming to terms with our own mortality (from death and dying to memorialization and commemoration) - that archaeology has the most to offer. Dealing with death is one phenomenon that unites society across time and space. Not only does archaeology allow for exploration of the range and diversity of ways in which different societies understood and mediated death, and commemorated the dead, it serves as a catalyst for meaningful conversations. The benefit of using examples of death practices from the deep (and more recent) past lies in the fact that they are somewhat removed from the present in time and space, and thus create a more distanced platform from which to explore themes of death, dying and bereavement, away from the imminence of death and the proximity of loved ones. As such, the material is much more likely to prompt conversations than attempting to broach the topic head-on. This was observed in the 'What will survive of us?' exhibition in Leicester during Dying Matters Awareness Week 2015, which explored a range of past death practices: conversations soon turned to personal accounts regarding the experiences of close relatives and individuals themselves (LOROS 2015). A similar phenomenon can be identified with the discussion of celebrity deaths, memorials of which have in 
recent times become increasingly apotheotic in nature (cf. GravesBrown and Orange 2017). In an open letter posted to the British Medical Journal online blog, for example, palliative care doctor Mark Taubert (2016) notes how the death of David Bowie helped to facilitate difficult conversations with a terminally ill patient.

\section{Methodology}

Building on these promising initial reactions, the Continuing Bonds Project - a two-year AHRC-funded collaboration (April 2016-July 2018) between archaeologists and palliative care professionals - explored what happened when the past was used to facilitate discussions around death, dying and bereavement in the present (Continuing Bonds Project 2018 ; Croucher et al. in prep.). Despite an increasing awareness of the issues amongst the general public (see above), many important conversations are still happening too late, when people are terminally ill in hospital. As such, Continuing Bonds was devised as a pilot project to target those working in palliative care; individuals more likely to broach these difficult topics of conversation with those nearing end of life. Participants included nursing staff, nursing students, and other end-of-lifecare professionals such as bereavement counsellors and faith practitioners (Figure 1), though future iterations of the project will seek to expand its reach into non-healthcare settings, including schools and lay audiences more generally.

Participant recruitment criteria included volunteer, student, trainee, registered and qualified practitioners working with people at the end of their lives, together with other groups of individuals, such as counsellors and chaplains, who come into contact with the dying and the bereaved. Dying and bereaved individuals were not eligible for inclusion in the project, due to the potentially sensitive and emotive nature of the material. The research was undertaken at the University of Bradford, DeMontfort University and LOROS Hospice Leicester, with most participants deriving from these geographical locations. Participants were invited to attend multiple workshops, since this provided an opportunity to examine in detail the journey of individual participants across a variety of themes and case studies, and to ascertain whether or not certain 
themes, and certain case studies, resulted in stronger or lesser reactions, or different types of conversations. All participants were given a 'participant information sheet' prior to attendance at a workshop and were required to sign and retain a consent form; this was true for each workshop, even when individuals had attended one previously. Approval for this research was granted by the University of Bradford ethics committee and the Health Research Authority, and the project was accepted onto the NHS clinical research network portfolio.

Archaeological case studies representing a variety of death practices and mortuary rituals were presented in a series of workshops, organized around four themes: 'Memorialisation and Legacy', 'Age and Circumstance of Death', 'Images of the Dead' and 'Ancestors'; to some extent these represent arbitrary divisions, and many of the case studies addressed more than one theme simultaneously. Workshops in each theme were run three times - at
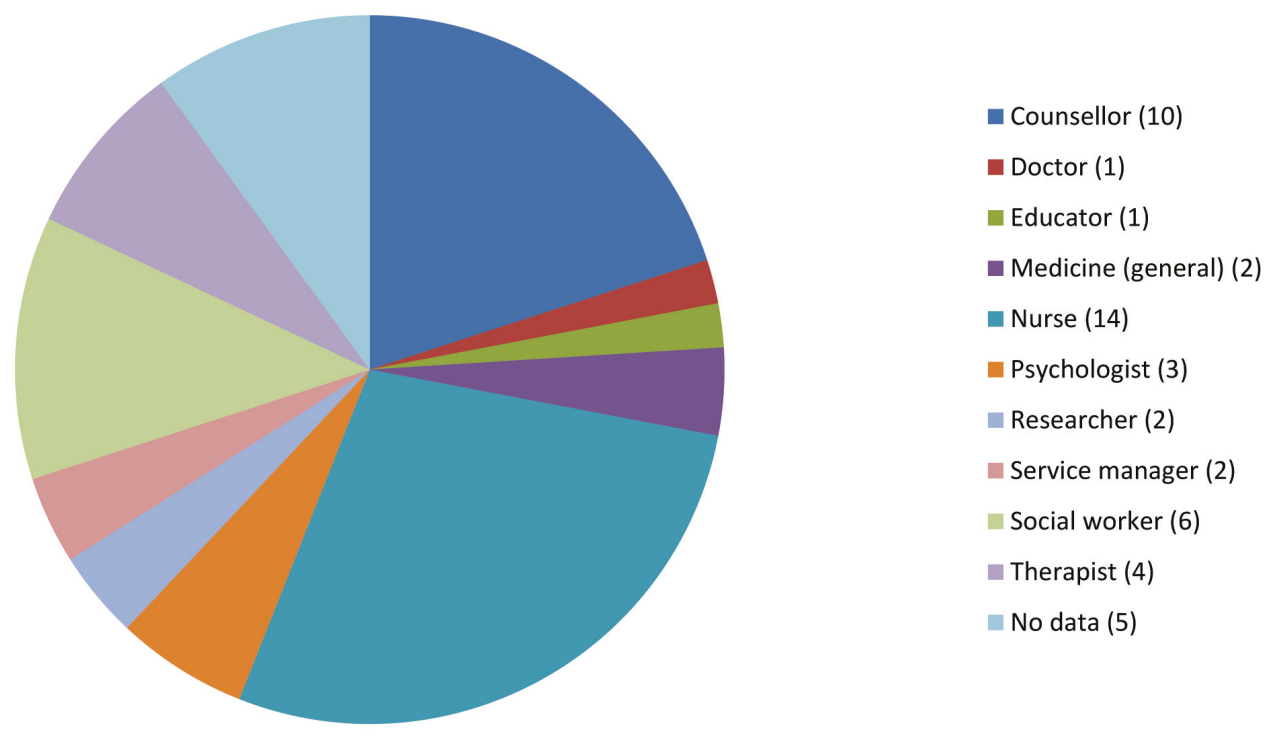

Figure 1: Professional backgrounds of the 50 unique participants who took part in workshop series 1 . Of these, $33(66 \%)$ were qualified professionals, 13 (26\%) were students and four ( $8 \%$ ) identified as 'other'. To simplify the graphic and aid visual analysis, certain categories have been amalgamated (e.g. occupational therapist and speech and language therapist have been combined under 'therapist'). 
LOROS Hospice and DeMontfort University in Leicester, and at the University of Bradford - to maximize recruitment and participant diversity (i.e. hospice workers, other healthcare professionals, counsellors and students). The content and composition of the case studies was fairly fluid, though each was designed to challenge preconceptions and prompt internal reflection. Each workshop was delivered using a 'thinking aloud' approach (Fonteyn and Fisher 1995; Boren and Ramey 2000) to a maximum of ten participants; this restricted number allowed participants sufficient opportunity to reflect and voice their opinions. 'Returners' formed a major component of the participant cohort, suggesting continued interest in and relevance of the workshops. Only data from returning participants' first workshop attendance is presented in this paper (see Figure 8).

The other major methodological driver behind workshop conception and delivery was that of 'action research' (e.g. Stringer 2013). Under this methodology, reflection and feedback on earlier stages of the project were used to inform the structure and delivery of later workshops. Changes included, but were not limited to, the inclusion of a greater diversity of multimedia elements (e.g. physical objects and audio-visual material), the decision to allow the participation of 'returners' in workshops (i.e. participation in more than one workshop), and changes to the four overarching themes in the second series of workshops. New workshop themes were designed to tease out greater depth of discussion on recurrent points of significance emerging from the first set of workshops. The new themes also reduced the potential for repetition of workshop content for 'returning' participants. The themes (which formed the basis for the second workshop series) were: 'Place', 'Legacy', 'Treatment of the Dead', and 'Objects and the Dead'. This paper will focus on findings from the first series of workshops only.

Reactions to the workshops, and to the case study materials presented, were captured in a number of ways. Questionnaires, filled out at the beginning of the workshop, collected quantitative demographic information such as age, gender, ethnicity and religion, as well as individuals' pre-workshop confidence in discussing death, dying and bereavement. Qualitative data included reasons for attending the workshop, and expected outcomes. The creation 
of unique participant numbers ensured a degree of anonymity of data (in so far as it allowed for subsequent collation, analysis and presentation without the use of personal names). During the workshop, immediate reactions to the case studies (which participants view for around six minutes each) were captured using Dictaphones and by asking participants to write responses on large pieces of flipchart paper (Figure 2). More in-depth reflection on the materials was facilitated through group discussion (Figure 3), which was captured using both Dictaphones and video cameras; the latter was used to aid transcription during data analysis. Questionnaires completed at the end of the workshop gathered quantitative data regarding post-workshop confidence in discussing death, dying and bereavement, together with qualitative feedback on if, how and why archaeology might be used to facilitate discussions in a contemporary end-of-life setting. Follow-up questionnaires, undertaken between one and three months after each workshop, collected the same kinds of qualitative and quantitative data, and assessed whether the workshops, and the reflections they prompted, had any lasting impact on participants, e.g. whether (and in what ways) they prompted a change in behaviour within or outside of professional practice. Optional participation in a followup interview explored these impacts in greater depth, and provided richer qualitative data for analysis.

Quantitative data was entered into a spreadsheet and analyzed using descriptive statistics. No tests to consider significance have been applied, since the study was not designed to assess change in this way. Qualitative data in free text on questionnaires, flip charts and from focus groups was analyzed thematically.

\section{The archaeological material}

Choosing the case studies

Case study material was presented via a series of 'stations', formed from a combination of images and text on laminated posters. The first workshop theme (Memorialisation and Legacy) comprised five 'stations' (Figure 4a); this was reduced down to three for subsequent themes to give participants more time with 


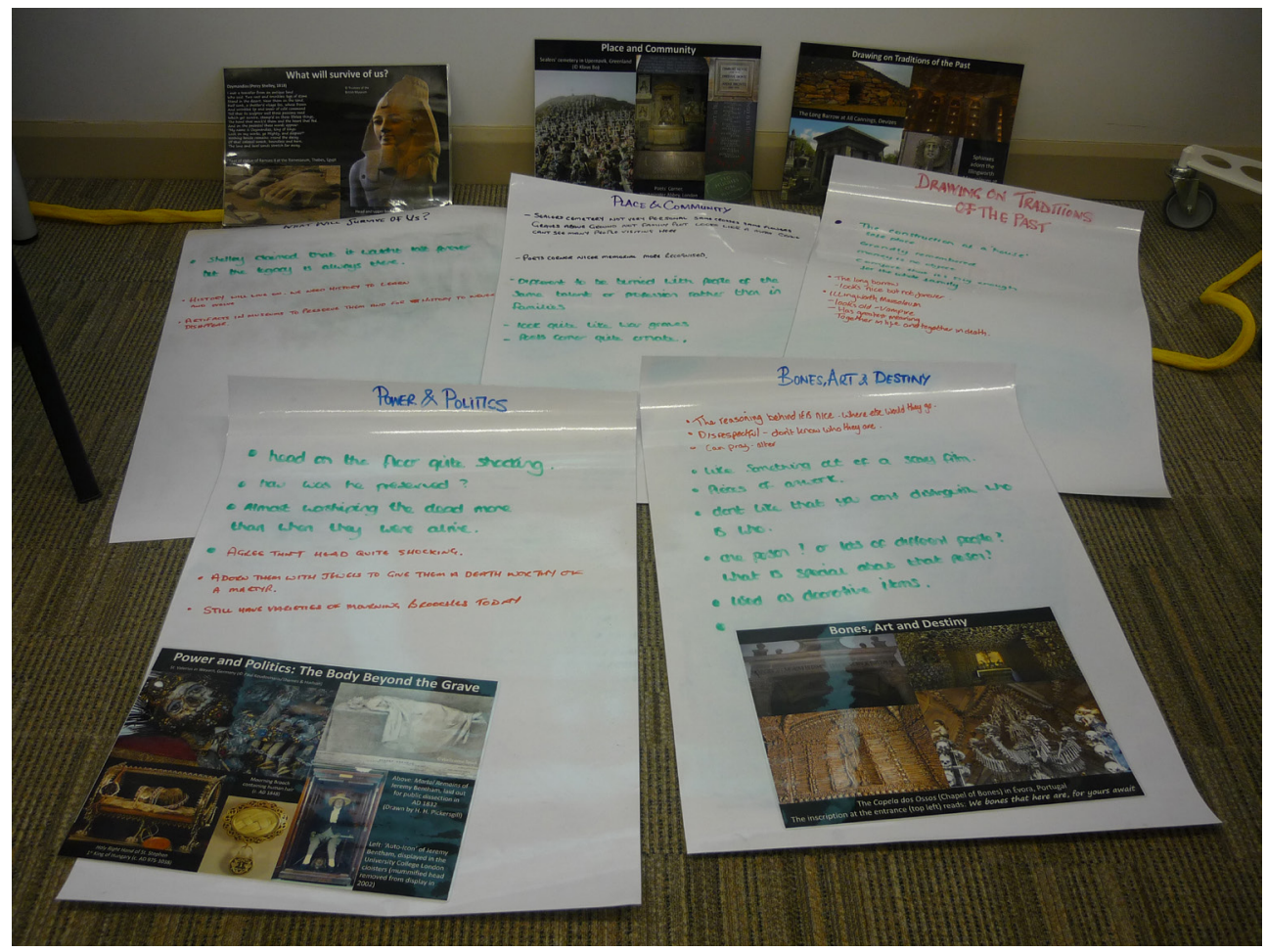

Figure 2: Case study material and participant reactions from workshop 3: Memorialisation and Legacy.

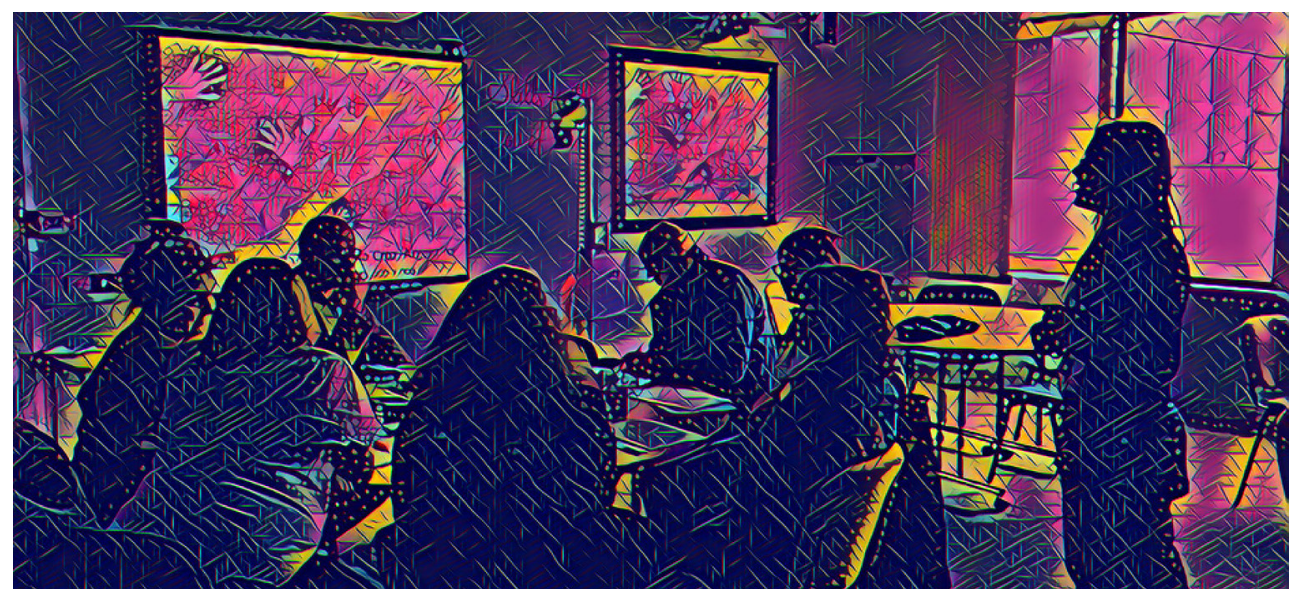

Figure 3: Group discussion and reflection on the archaeological case study materials in workshop 1: Memorialisation and Legacy; individuals have been anonymized to protect their identity. 
the materials. Where possible, other media - including physical reconstructions and audio-visual materials (Figure 4b) - were included, with a view to exploring their pedagogic impact. Each station addressed a different sub-theme within the overall theme of the workshop (Table 1), though this distinction was occasionally (and sometimes deliberately) ambiguous. Each comprised between one and four individual case studies; again, reduced in number over the course of the workshops in the interests of time, as part of the project's action research methodology. Choosing successful case studies relied on a number of factors: visually striking images, a 'story' which could be conveyed concisely, and where possible, case studies in which the text had the power to augment or challenge initial reactions to the images (Figure 5). Multimedia elements, such as a 3D-printed skull and facial reconstruction, and an audiovisual piece, were added to the Images of the Dead and Ancestors workshops respectively, in response to questionnaire feedback from the first two workshops. Materials were also chosen which, together, had wide chronological and geographical coverage, and which encouraged participants to compare and contrast case studies, both within and between stations (Figure 5); the latter helped to identify common and recurrent themes which could be examined in greater depth in the second set of workshops. Ethnographic materials were also included to demonstrate that diverse mortuary practices are a feature of societies across the globe today, not just those in the past.

Case studies - which included images of human remains, objects belonging to and made from the dead, places of commemoration, public/private memorials, and less well-known rites and rituals - were designed to challenge existing preconceptions and encourage a more holistic and open-minded view of mortuary practices. It came as no surprise, however, that many of the strongest reactions appeared to correspond with those materials that challenged participants' culturally embedded concepts of personhood and identity. The aim of the Continuing Bonds Project was not to promote uptake of the same mortuary rituals and social concepts of self as those of the past, but to expose participants to the range of ways in which individuals (past and present) experienced death, dying and bereavement. Through exploration of difference in practice, recurrent themes emerged. Not least, the creation and maintenance of continuing bonds between the 
living and the dead (Klass et al. 1996), which manifest themselves a variety of ways: from the retrieval and display of human remains, to the curation of photographs, artefacts, memorials and, more recently, digital platforms such as Facebook legacy pages. Choice (i.e. an individual's 'agency') and place of burial were also strong recurring themes in workshop discussions (Figure 5), and are likewise common foci for discussion in mortuary archaeology today (e.g. Gillespie 2001; Williams 2004; Brück 2006; Giles 2008; Finlayson 2010; Fowler 2013).
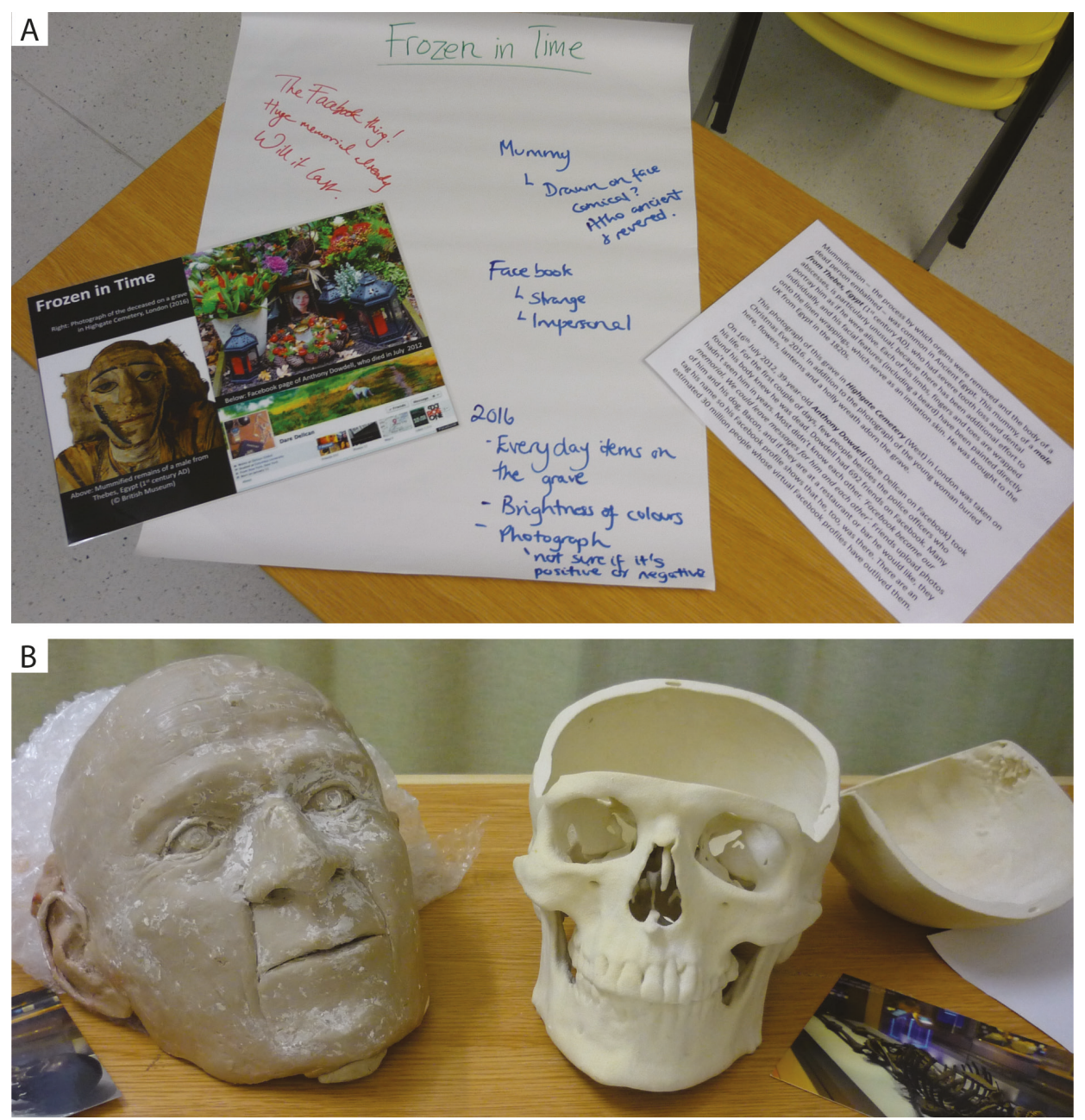

Figure 4: 'Stations' in workshop 15: Images of the Dead; a) conventional two-dimensional laminated poster; b) three-dimensional print and facial reconstruction of Gristhorpe Man (courtesy University of Bradford). 


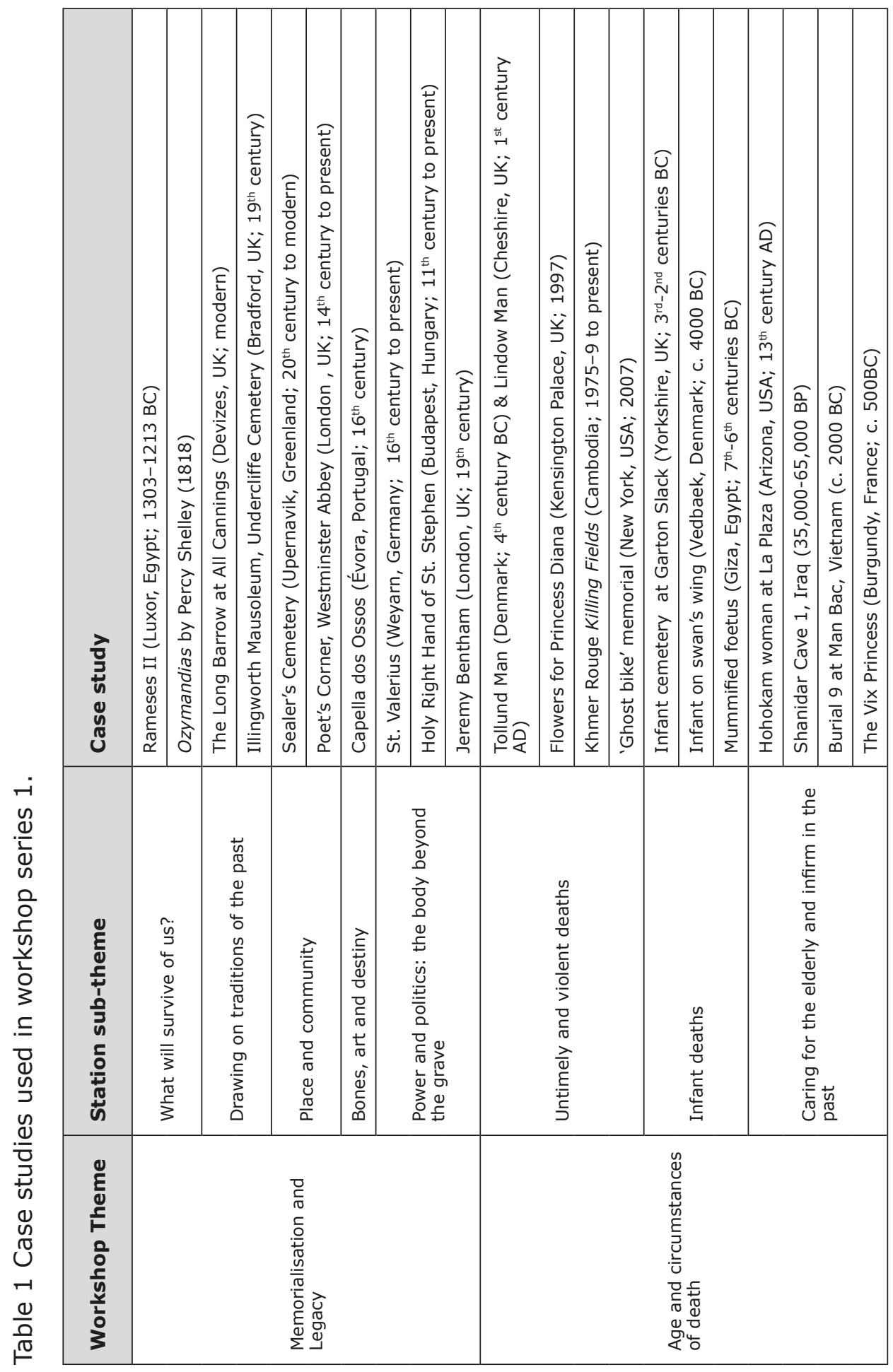


BÜSTER et al. - From Plastered Skulls to Palliative Care - 261

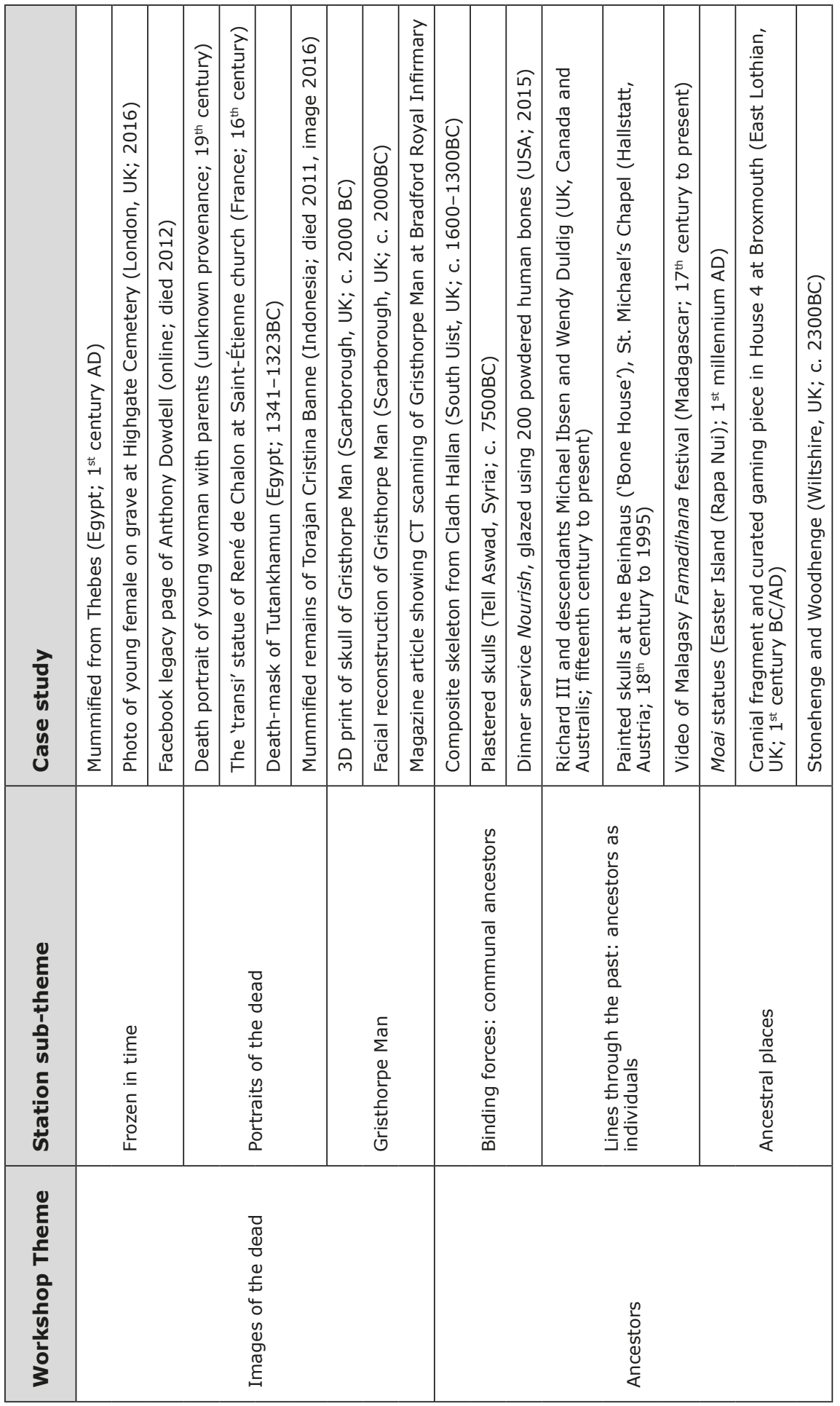






Figure 5: Structure of the workshops and station case study material, together with emergent and recurring themes in participant reactions and discussion points.

\section{Exploring reactions}

Another facet of archaeological material is its ability to act as a mirror to ourselves as individuals. Most culturally embedded perceptions and practices are entirely subconscious; what Bourdieu (1977) terms habitus. This is particularly so in relation to the ways 
in which death is understood and perceived, since it is inherently bound up with the ways in which people understand and articulate their place in the world. Indeed, an examination of death practices not only has the potential to provide insights into the way in which a society views death, but also, how it views life. The allocation of death to specialists and the shielding of the living from the physical processes associated with death, suggests that in modern, Western (and increasingly secularized) cosmology, death is seen as very much separate from life, not a part of it (cf. Tarlow 1999). Certainly, this is reflected in the language used to describe the dead, including phrases such as 'passed on', 'passed away' and even 'lost' (Quested and Rudge 2003: 554). Yet, as we have seen, emerging practices particularly those surrounding digital legacies - suggest something less concrete, and resonate more closely perhaps with some of the death practices of the past, which seek to maintain closer ties between the living and the dead.

Language is central to conversations surrounding death, dying and bereavement. In this regard, the Continuing Bonds Project workshops prompted participants to explore the ways in which society has become accustomed to talking about these sensitive topics. Terms such as 'respect' and 'disrespect' were commonplace in participants' reactions to the materials, and it was interesting to unpick these during group discussion. Through their own selfreflection, participants came to understand these as culturally embedded terms. By exploring which practices they found 'acceptable' and 'unacceptable', participants also cast light on what they wanted for themselves, and for their families, particularly regarding long-term obligations of memorialization on the part of loved ones (tending graves and visiting favourite places, for example).

As noted previously, a powerful and consistent reaction concerned perceptions of personhood. Many participants reacted strongly and negatively (Figure 6) to the Capella dos Ossos - a chapel and ossuary in Portugal decorated with the disarticulated bones of around five thousand individuals - with terms such as 'disrespectful' and 'scary' used frequently. For the project participants, social identity was inherently bound to their individual, physical bodies, and challenges to this integrity made for uncomfortable viewing, 


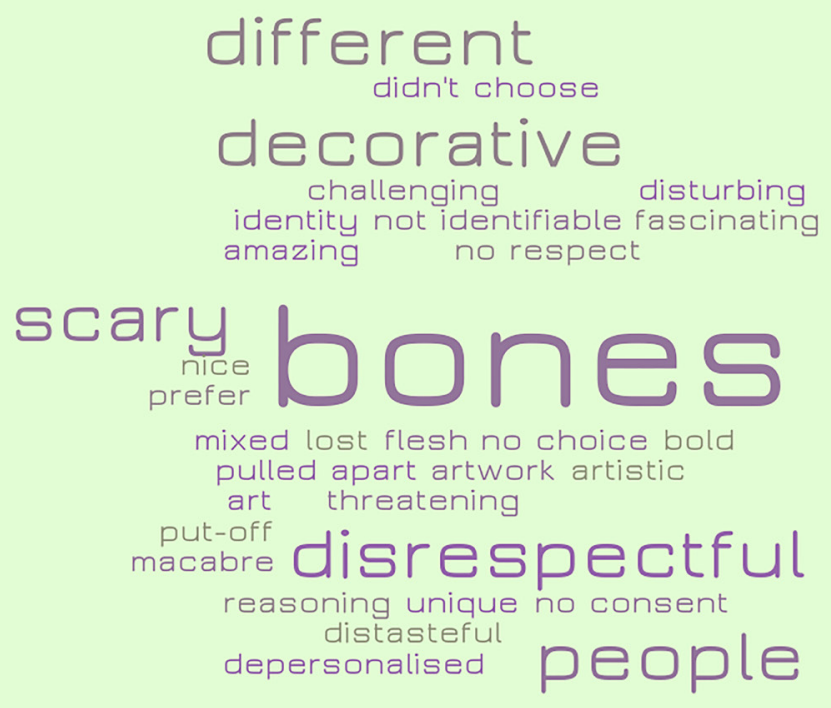

Word] ItOut

Figure 6: Word-cloud generated from participants' reactions to the Capella dos Ossos case study. The larger the word, the higher the frequency with which it was used by participants.

with one participant commenting: "Don't like that the[y] haven't been left whole". Despite the strength of the adverse reactions to this treatment of the dead, self-reflection amongst participants was still clearly evident: "How would I feel about bones mixed in with others. Is this different from ashes? What makes it different? Would I mind?". This suggests that even initially challenging material has a role to play beyond 'shock factor'.

Interestingly, the materials with which participants chose, and chose not, to engage appear to reveal much about their inbuilt perceptions of death and dying. One particularly illuminating example of this was the 'Portraits of the Dead' station (Table 1 ), which formed part of the 'Images of the Dead' workshops. Notes on the flipchart paper primarily regarded the Victorian death portrait and death-mask of Tutankhamun in some detail, whilst the sixteenth-century transi-statue of Réne de Chalon in Saint-Étienne (France), and the Torajan mummy in particular 
(Figure 7), received less attention. Both of these latter images can be considered liminal - that is, they are difficult to categorize as either alive or dead; this is especially true of the Torajan mummy, who retains flesh and is dressed in everyday clothes, as if alive. Pressed further on this specific image, some participants claimed to have noticed only the living individuals, not the mummy. This reveals something very specific about the central role that categorization plays in the ways in which death is perceived and understood. Liminality is a central theme in funerary archaeology (e.g. Barrett 1988; Armit 2012; Fowler 2013), and, as noted at the beginning of this paper, could lie behind much of what nurses find emotionally challenging in the care of, for example, brain dead patients (cf. Crandall 1987; Johnson 1992; Hadders 2007; Büster et al. in prep.).

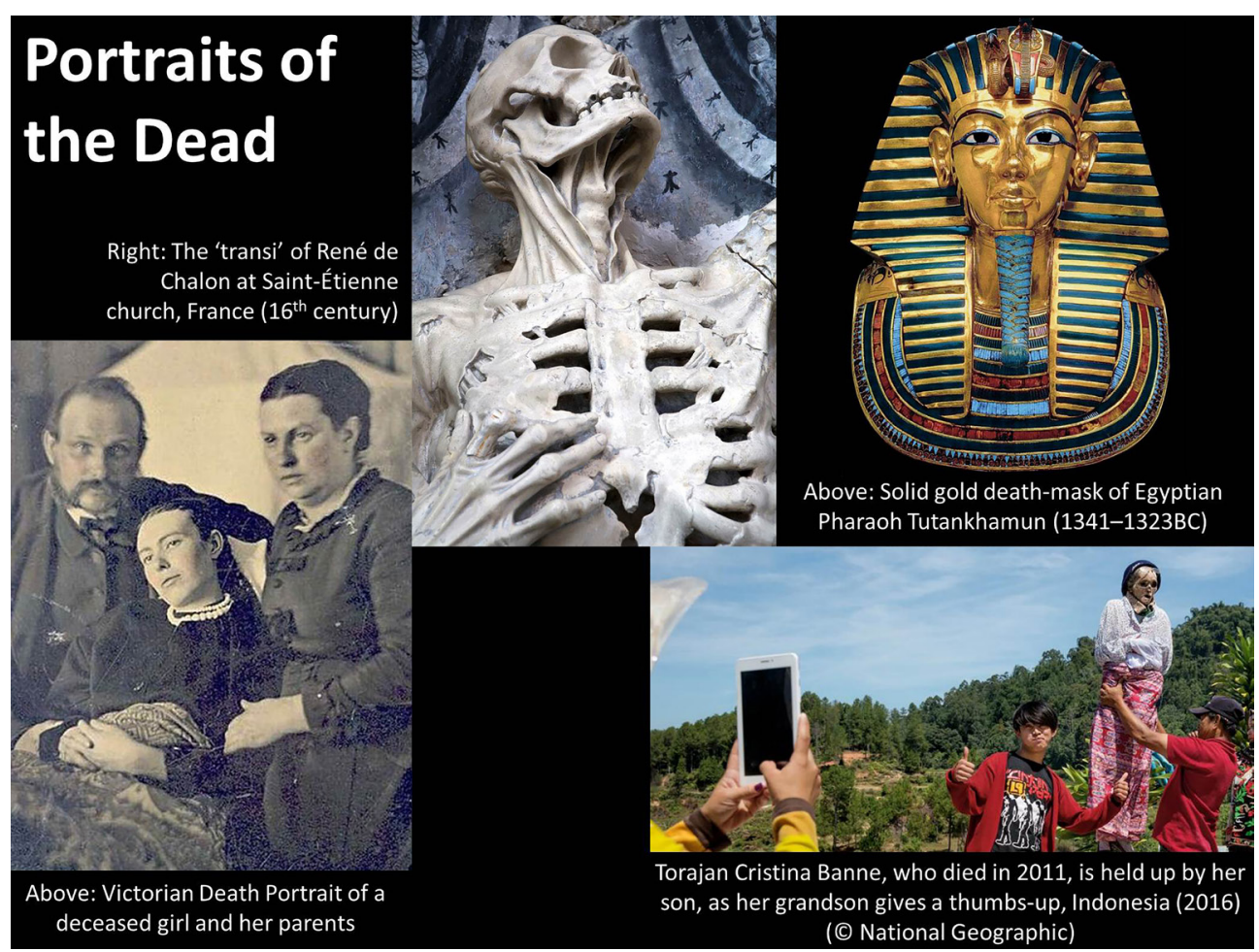

Figure 7: 'Portraits of the Dead' station featured in Images of the Dead workshop theme. 


\section{Assessing impact}

\section{Changing ways of thinking}

In this exploratory study, we sought only to evaluate participants' own perceptions of the impact of the workshop. Participants were asked to think about themselves in relation to death, dying and bereavement, and to assess on a Likert scale: a) their levels of confidence in discussing death, dying and bereavement before and after the workshops; b) whether the case study materials made them think differently about death, dying and bereavement; and c) whether they thought that the workshop would affect the ways in which they approached the subject in their professional roles (Figure 8). In follow-up questionnaires and interviews, we will persistence of impact, actions, and reflections on changes in behaviour taken by participants as a result of attending the workshops, and explore which components of the workshops in particular had the most profound affect.

Only $10 \%$ (5/50) participants 'disagreed' or 'strongly disagreed' that they felt confident in talking about death, dying and bereavement before the workshops, with a further $12 \%$ (6/50) saying either that they 'didn't know', or that they 'neither agreed nor disagreed'. Nevertheless, despite 78\% (39/50) of the participants 'agreeing' or 'strongly agreeing' that they felt confident talking about death, dying and bereavement prior to the workshops, 48\% (24/50) said they 'agreed' or 'strongly agreed' that this confidence had increased after the workshops (Figure 8).

Significantly, $90 \%(45 / 50)$ of participants said that the workshops had made them think differently about death, dying and bereavement, while a further $50 \%$ (25/50) said that it would impact upon the way in which they approached the topic in their future professional practice (Figure 8 ). Only 4\% (2/50) of individuals suggested that the workshop would have little or no impact on their future behaviour, with the remaining $46 \%$ suggesting that they did not yet know (i.e. checking the 'don't know' or 'neither agree nor disagree' option) (Figure 8). Indeed, it may be that some participants were unable to assess the impact of the workshop immediately. Some themes and concepts may require further selfreflection and quiet contemplation, particularly if they pressed upon 
a particularly personal or emotive experience. Other individuals may have felt that the true impact of the workshop would not become apparent until the next 'real life' situation, when they were required to broach these difficult topics of conversation with a dying patient and their relatives. It is for this reason that participants were asked to complete a three-month follow-up questionnaire, in order to determine whether or not the workshops had a lasting or developing impact on them.

Impact was not only measured in terms of 'quantity' (i.e. the number of participants who noted a change), it was also measured in terms of 'depth' (i.e. the level of change, irrespective of the number of participants who experienced this). In order to examine this latter dimension, it is worth tracking the immediate pre- and post-workshop journeys of a number of individuals. One participant,

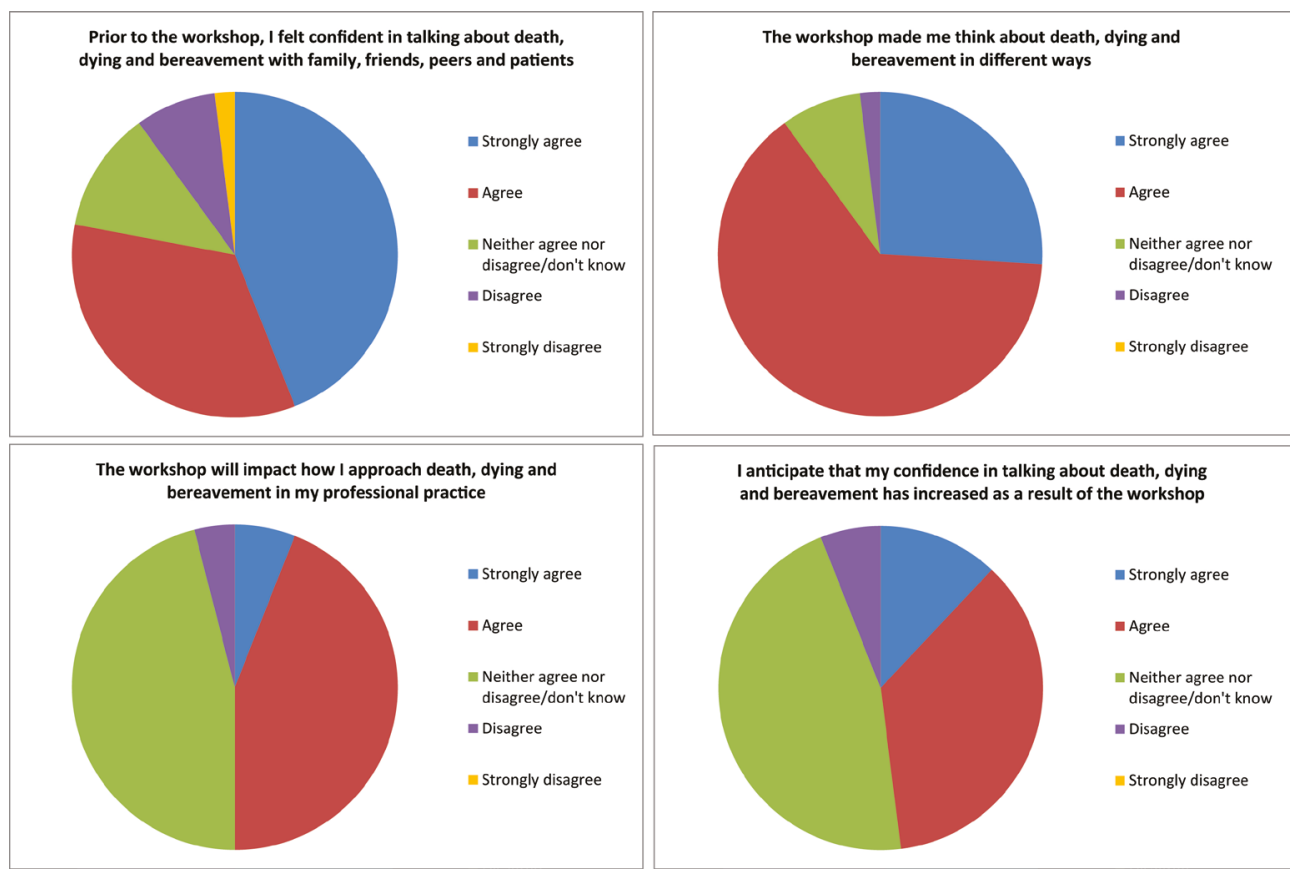

Figure 8: Analysis of responses to questions regarding pre- and postworkshop confidence of participants when discussing death, dying and bereavement, together with whether or not the workshops had an impact on the ways in which participants thought about and would broach the subject with patients. 
for example, 'strongly disagreed' that they were confident in talking about death, dying and bereavement before the workshop. This same participant agreed that the workshop had both changed the way they thought about the topic and the way in which they would approach the subject with patients in future. Having said that, this person did not know whether their confidence had necessarily increased immediately post-workshop. Meanwhile, though another participant 'strongly agreed' that they were confident about discussing death, dying and bereavement before the workshop, and 'neither agreed nor disagreed' that this confidence had changed post-workshop, they nevertheless 'strongly agreed' and 'agreed' respectively that the workshop had made them think differently and would impact the way in which they approached it with patients in future. The two participants who disagreed that the workshops would impact on their confidence discussing death, dying and bereavement in the future, both 'strongly agreed' that they were already confident in broaching the topic pre-workshop.

\section{What can the past teach the present, and the present teach the past?}

Archaeologists are conscious not to impress modern socio-cultural perspectives onto the past, and have rightly criticized approaches that seek to 'put us in their shoes' (see, for example, Brück 2005 for consideration of the potentials and limitations of phenomenology in archaeology). The Continuing Bonds Project has demonstrated, however, that some phenomena (not least, the challenges of dealing with death, dying and bereavement) are recurring concepts which transcend time and space. Within a diverse range of death practices, creating and maintaining 'continuing bonds' between the living and the dead appears to be one of the more enduring practices (see Croucher 2017). This is not to deny that the strategies and nuances of how these bonds are constructed change and vary significantly over time and space, from recreating in plaster the face of a loved one, for example, to keeping an old photograph in a locket, and posting regularly on a legacy Facebook page.

The protracted nature of mortuary rites of the past - such as the mummification of bodies in later prehistoric Britain (for example, 
at Cladh Hallan; Parker Pearson et al. 2005) or the exhumation and plastering of skulls in the Neolithic Middle East (Croucher 2017) (Table 1) - demonstrates that grief and bereavement are complex, long-term processes which take time to negotiate. In many societies, the physical body serves a central role, as a tangible way of charting the transition from living individual to communal ancestor. The outsourcing and medicalization of death in many contemporary societies has served to hide the harsh realities that death brings with it. This sequestering of the dead has also, however, separated the living from one of the fundamental ways in which this inevitable part of life is acknowledged. Indeed, caring for the dead is one of the final positive acts that individuals can perform for their loved ones, and increasingly, legislation is encouraging relatives to take part in these 'last offices' (Johnson 1992; Martin and Bristowe 2015).

It is not just the human body that can be used to form continuing bonds with the dead however. Archaeologists are well aware of the power of material culture in conveying social messages, both positive and negative. Where a photo of the deceased - like the plastered skulls of Neolithic Levant - might bring comfort to the bereaved, other objects (particularly personal items belonging to the deceased) are more problematic: these might be too embedded in their social identity to be passed on for use by someone else, or discarded like rubbish. This is an experience recalled by one of the project participants (number 20) during group discussion:

"...my mum died very suddenly when I was [age], and just before she died, she'd bought a big tub of Horlicks which she gave to me for some reason... and I could not throw this away. It was in the cupboard for five years! And it was solid. But because she'd bought it, it became like an artefact. I did throw it away in the end, I suppose it was a symbol of my getting through the grief..."

It is increasingly recognized that much of what is excavated by archaeologists represents 'structured deposits': material very deliberately assembled and buried in specific, symbolic ways (cf. Hill 1995). Querns - the quintessential everyday object - turn

1 Some details have been changed to protect the identity of the participant. 
up, for example, in later prehistoric Britain, in the most unusual of places and are often deliberately fragmented (Watts 2014). Are these, like the jar of Horlicks cited above, so socially charged that they demand special treatment? Does their breakage and deposition signal a pivotal moment in the grieving process? If so, then all archaeologists-and not just those interacting directly with dead bodies-could be seen as 'death-dealers' (cf. Giles and Williams 2016, 10); the latest in a long line of individuals to curate the material remains (and tell the stories) of the dead. By extension, it is not just how we research and present the skeletal remains of the long-dead that is central to contemporary perceptions of mortality (ibid, 4), but arguably all interactions with the material past both within and outside of the 'mortuary archaeology' sub-discipline.

\section{Conclusions}

Archaeology (and mortuary archaeology in particular) has an important role to play in addressing some of the most pressing issues in contemporary society. Though the Continuing Bonds Project does not seek to transplant the death practices and mortuary rituals of the past into the present, it has shown that archaeology can be used to provide a safe platform from which to embark on discussions of death, dying and bereavement in the present. The workshops have prompted personal reflection on culturally embedded attitudes (and prejudices), which may in turn influence the ways in which these important topics of conversation are raised in end-of-life care settings. Future projects will expand this initial research to wider lay audiences, with particular focus on educational resources for school children, so as to help normalize these most fundamental of conversations from an early age. The power of archaeology lies in its diversity and its promotion of selfreflection on a number of contemporary issues, including the most enduring and pressing of all: our own mortality. 


\section{Acknowledgements}

The Continuing Bonds Project is led by Karina Croucher (Lecturer in Archaeology at the University of Bradford), with co-investigators Laura Green (Lecturer in Cancer, Palliative and End of Life Care at the University of Bradford) and Christina Faull (Professor in Palliative Medicine, LOROS Hospice Leicester). Lindsey Büster and Jennifer Dayes are post-doctoral researchers on the project and have backgrounds in archaeology and psychology respectively. The project is funded by the Arts and Humanities Research Council. The project team is indebted to all of the participants who have taken part in workshops, and would also like to thank Sarah Tarlow for collaboration in the 'What will survive of us?' exhibition (2015).

\section{References}

Armit, I. 2012. Headhunting and the Body in Iron Age Europe. Cambridge, Cambridge University Press.

Barrett, J. C. 1988. The living, the dead, and the ancestors: Neolithic and Early Bronze Age mortuary practices. In J. C. Barrett and I. A. Kinnes (eds), The Archaeology of Context in the Neolithic and Bronze Age: Recent Trends, Sheffield, University of Sheffield, 30-41.

Bourdieu, P. 1977 [trans. R. Nice]. Outline of a Theory of Practice. Cambridge, Cambridge University Press.

Bowlby, J. 1980. Attachment and Loss, Vol. 3. Loss: Sadness and Depression. London, Hogarth.

Brück, J. 2005. Experiencing the past? The development of a phenomenological archaeology in British prehistory. Archaeological Dialogues 12(1), 45-72.

Brück, J. 2006. Death, exchange and reproduction in the British Bronze Age. European Journal of Archaeology 9, 73-101.

Buckman, R. 1993. Communication in palliative care: a practical guide. In D. Doyle, G. W. C. Hanks and N. MacDonald (eds), Oxford Textbook of Palliative Medicine. Oxford, Oxford University Press, 47-61. 
Büster, L., Croucher, K., Green, L. and Faull, C. In prep. Straddling worlds: the role of nurses as ritual specialists in caring for the dead and dying. Manuscript in preparation.

Campos-Calderón, C., Montoya-Juárez, R., Hueso-Montoro, C., Hernández-López, E., Ojeda-Virto, F. and García-Caro, M. P. 2016. Interventions and decision-making at the end of life: the effect of establishing the terminal illness situation. BMC Palliative Care 15(1), 91. DOI: 10.1186/s12904-016-0162-z.

Chapple, A., Ziebland, S. and Hawton, K. 2015. Taboo and the different death? Perceptions of those bereaved by suicide or other traumatic death. Sociology of Health \& IIlness 37(4), 610-25.

Continuing Bonds Project. 2018. Continuing bonds: archaeology meets end-of-life care. Retrieved on 26 June 2018 from WWW https://continuingbonds.live

Cox, K., Bird, L., Arthur, A., Kennedy, S., Pollock, K., Kumar, A., Stanton, W. and Seymour, J. 2013. Public attitudes to death and dying in the UK: a review of published literature. British Medical Journal Supportive \& Palliative Care 3, 37-45.

Crandall, B. C. 1987. Identifying dilemmas in caring for brain-dead organ donors in the OR. AORN Journal 46(5), 844-946.

Croucher, K. 2017. Keeping the dead close: grief and bereavement in the treatment of skulls from the Neolithic Middle East. Mortality 23(2), 102-20.

Croucher, K., Büster, L., Dayes, J., Green, L., Raynsford, J. and Faull, C. In prep. Continuing bonds: archaeology meets end of life care. Manuscript in preparation.

DH: Department of Health. 2008. End of Life Care Strategy: Promoting High Quality Care for All Adults at the End of Life. London, Department of Health.

Dying Matters. 2018. Awareness Week. Retrieved on 26 June 2018 from WWW https://www.dyingmatters.org/AwarenessWeek

Finlayson, B. 2010. Agency in the Pre-Pottery Neolithic A. In D. Bolger and L. C. Maguire (eds), The Development of Pre-State 
Communities in the Ancient Near East: Studies in Honour of Edgar Peltenburg, Oxford, Oxbow Books, 141-46.

Fowler, C. 2013. Identities in transformation: identities, funerary rites, and the mortuary process. In S. Tarlow and L. Nilsson Stutz (eds), The Oxford Handbook of the Archaeology of Death and Burial. Oxford, Oxford University Press, 511-26.

Gellie, A., Mills, A., Levinson, M., Stephenson, G. and Flynn, E. 2015. Death: a foe to be conquered? Questioning the paradigm. Age and Ageing 44, 7-10.

Giles, M. 2008. Identity, community and the person in later prehistory. In J. Pollard (ed.), Prehistoric Britain. Oxford, Blackwell, 330-50.

Giles, M. and Williams, H. 2016. Introduction: mortuary archaeology in contemporary society. In $M$. Giles and H. Williams (eds), Archaeologists and the Dead. Oxford, Oxford University Press, 1-18.

Gillespie, S. D. 2001. Personhood, agency, and mortuary ritual: a case study from the Ancient Maya. Journal of Anthropological Archaeology 20, 73-112.

Graves-Brown, P. and Orange, H. 2017. "The stars look very different today": celebrity veneration, grassroot memorials and the apotheosis of David Bowie. Material Religion 13(1), 121-23.

Hadders, H. 2007. Dealing with the dead patient at the intensive care unit. Mortality 12(3), 207-22.

Hill, J. D. 1995. Ritual and Rubbish in the Iron Age of Wessex: A Study on the Formation of a Specific Archaeological Record. British Archaeological Reports (British Series) 242. Oxford, Tempus Reparatum.

Hopkinson, J. B., Hallett, C. E. and Luker, K. A. 2005. Everyday death: how do nurses cope with caring for dying people in hospital? International Journal of Nursing Studies 42, 125-33.

Impermanence. 2018. Death Cafe. Retrieved on 26 June 2018 from WWW http://deathcafe.com/ 
274 - BÜSTER et al. - From Plastered Skulls to Palliative Care

Johnson, C. 1992. The nurse's role in organ donation from a brainstem dead patient: management of the family. Intensive and Critical Care Nursing 8, 140-48.

Kellehear, A. 2007. A Social History of Dying. Cambridge, Cambridge University Press.

Kent, B., Anderson, N. E. and Owens, R. G. 2012. Nurses' early experiences with patient death: The results of an on-line survey of Registered Nurses in New Zealand. International Journal of Nursing Studies 49, 1255-65.

Klass, D., Silverman, P. R. and Nickman, S. L. 1996. Continuing Bonds: New Understandings of Grief. London, Taylor and Francis.

Kübler-Ross, E. 1969. On Death and Dying. London, Routledge.

LOROS. 2015. Dying Matters Awareness at LOROS. 2015: What will survive of us? Retrieved on 23 May 2018 from WWW https:// www.loros.co.uk/education-training-research/research/dyingmatters-awareness-at-loros/

Luce, J. M. 2010. End-of-life decision making in the intensive care unit. American Journal of Respiratory and Critical Care Medicine 182(1), 6-11.

Martin, S. and Bristowe, K. 2015. Last offices: nurses' experiences of the process and their views about involving significant others. International Journal of Palliative Nursing 21(4), 173-78.

Parker Pearson, M., Chamberlain, A., Craig, O., Marshall, P., Mulville, J., Smith, H., Chenery, C., Collins, M., Cook, G., Craig, G., Evans, J., Hiller, J., Montgomery, J., Schwenninger, J-L., Taylor, G. and Wess, T. 2005. Evidence for mummification in Bronze Age Britain. Antiquity 79(305), 529-46.

Pushing Up Daisies. 2018. Retrieved on 26 June 2018 from WWW http://www.pushingupdaisies.org/

Quested, B. and Rudge, T. 2003. Nursing care of dead bodies: a discursive analysis of last offices. Journal of Advanced Nursing 41(6), 553-60. 
SGHD: Scottish Government Health Directorates. 2008. Living and Dying Well: A National Action Plan for Palliative and End of Life Care in Scotland. Edinburgh, Scottish Government Health Directorates.

Sofka, C. J., Noppe Cupit, I. and Gilbert, K. R. 2012. Death, Dying and Grief in an Online Universe: For Counsellors and Educators. New York, Springer.

Stringer, E. T. 2007. Action Research. Third edition. Thousand Oaks/ London, Sage Publications.

Stroebe, M. S., Abakoumkin, G., Stroebe, W. and Schut, H. 2012. Continuing bonds in adjustment to bereavement: impact of abrupt versus gradual separation. Personal Relationships 19(2), 255-66.

Tarlow, S. 1999. Wormie clay and blessed sleep: death and disgust in later historic Britain. In S. Tarlow and S. West (eds), The Familiar Past? Archaeologies of Later Historical Britain. London, Routledge, 183-98.

Taubert, M. 2016. A thank you letter to David Bowie from a palliative care doctor. BMJ Supportive \& Palliative Care Blog. Retrieved on 23 May 2018 from WWW http://blogs.bmj.com/ spcare/2016/01/15/a-thank-you-letter-to-david-bowie-from-apalliative-care-doctor/

Walter, T. 1991. Modern death: taboo or not taboo. Sociology 25(2), 293-310.

Walter, T. 1996. A new model of grief: bereavement and biography. Mortality 1(1), 7-25.

Watts, S. R. 2014. The Life and Death of Querns: The Deposition and Use-Contexts of Querns in South-Western Britain from the Neolithic to the Iron Age. Southampton Monographs in Archaeology (New Series) 3. Southampton, Highfield Press.

Williams, H. 2004. Death warmed up: the agency of bodies and bones in early Anglo-Saxon cremation rites. Journal of Material Culture 9(3), 263-91. 
276 - BÜSTER et al. - From Plastered Skulls to Palliative Care

World Health Organisation. 2012. Definition of Palliative Care.

Retrieved on 25 August 2017 from WWW http://www.who.int/ cancer/palliative/definition/en/ 